\title{
Utilização de grupos virtuais no processo de pesquisa para a elaboração curricular de cursos técnicos
}

\author{
Cristina Morishita do Amaral ${ }^{1}$ \\ ${ }^{1}$ Coordenação de Informática - Etec Dra. Ruth Cardoso (Centro Paula Souza) \\ Praça Coronel Lopes, 82 - São Vicente - SP - Brazil \\ cristina.morishitadetec.sp.gov.br
}

\begin{abstract}
This article aims to reflect as virtual groups can collaborate with the research process for curriculum development of technical level. It discusses how the WhatsApp, can be used in mapping and propagation of information between course coordinators and curriculum development teams.
\end{abstract}

Resumo. Este artigo tem por objetivo refletir como grupos virtuais podem colaborar com o processo de pesquisa para a elaboração curricular de nível técnico. Aborda como o WhatsApp, pode ser usado no mapeamento e propagação da informação entre coordenadores de curso e equipes de elaboração curricular.

\section{Introdução}

O desenvolvimento curricular de nível técnico é construído tendo o trabalho como princípio educativo. Segundo RAMOS (2008), "o trabalho como princípio educativo, equivale dizer que o ser humano é produtor de sua realidade e, por isto, se apropria dela e pode transforma-la [...]. Em síntese, o trabalho é a primeira mediação entre o homem e a realidade material e social." o que mostra o papel importante da formação profissional.

Philippe Perrenoud (2013), ao descrever as transformações do trabalho e como as tecnologias transformam e influenciam esse processo, afirma que "No mundo do trabalho, desenvolver as próprias competências deixou de ser uma escolha, passando a ser uma simples condição. São cada vez mais raros os setores nos quais é possível sobreviver sem aprender".

No setor tecnológico isso é evidente, ao observarmos o ritmo frenético em que novas tecnologias surgem, se adaptam e são remodeladas, se torna um desafio a construção de currículos que consigam acompanhar as tendências e atender as múltiplas realidades sociais e profissionais, no que tange a formação.

\section{Elaboração Curricular de Nível Técnico}

Cada instituição tem autonomia na construção de seus currículos, obviamente respeitando as diretrizes estabelecidas no perfil profissional definido pelo MEC para a referida habilitação. No entanto, independente da metodologia empregada, o processo de pesquisa junto a órgãos de classe, empresas, estudantes e professores é essencial para o mapeamento das necessidades do curso em desenvolvimento. Isso se faz necessário, em especial no caso de instituições que oferecem as mesmas habilitações em diversas regiões. 
V Congresso Brasileiro de Informática na Educação (CBIE 2016)

Anais do XXVII Simpósio Brasileiro de Informática na Educação (SBIE 2016)

Segundo NETO (2010), "O currículo é potencial, é uma construção particular dentro de uma relação de significados e contextos diferenciados. Assim, o conhecimento está ligado ao currículo, como o conhecimento está ligado ao ser humano.", ignorar os contextos em que o currículo está inserido é ignorar o fator humano dessa equação. Visualizar os potenciais benefícios oriundos em especial da experiência dos docentes é importante dos entendimentos concernentes a construção do profissional e a compreensão das suas necessidades de formação.

Tendo em vista essa realidade, buscou-se uma estratégia para o uso de grupos virtuais para aproximar o processo de elaboração curricular dos coordenadores de cursos que por sua vez são capazes de articular essas informações em suas regiões e preparar as escolas para as alterações curriculares.

O presente estudo é parte do resultado do trabalho de pesquisa de elaboração curricular do eixo de Informação e Comunicação no Centro Paula Souza iniciado em julho de 2015.

\section{Grupos Virtuais}

Segundo os estudos realizados pelo Datafolha em 2014, 43 milhões de brasileiros acessam a internet por dispositivos móveis; considerando que o aplicativo WhatsApp tinha 38 milhões de contas ativas no Brasil em 2014, podemos concluir que grande parte dos brasileiros que utilizam recursos de internet usam esse aplicativo. Podemos afirmar que, dos 98 coordenadores de informática pesquisados, todos utilizavam esse aplicativo.

Como parte do processo de pesquisa para a elaboração curricular dos cursos técnicos de Informática e Desenvolvimento de Sistemas, foram criados grupos virtuais para a captação de sugestões e propagação de informações entre coordenadores de curso e a equipe de elaboração curricular. Para garantir a eficiência do processo, foram criados dois grupos: um utilizando a plataforma institucional e aberto a todos os professores e outra exclusiva para coordenadores utilizando o WhatsApp. Este artigo aborda o segundo grupo.

Inicialmente todos os coordenadores foram adicionados ao mesmo grupo, o que resultou em alguns problemas como: mensagens fora de hora, incômodo dos primeiros adicionados ao grupo, discussões fora do contexto e constantes relatos de experiências pessoais. Foi observado que muitos participantes se tornaram omissos e possivelmente silenciaram o grupo. Também o grande número de mensagens tornava difícil acompanhar as discussões. Tendo isso em vista, o grupo foi fragmentado em 6 grupos regionais contendo $10-25$ participantes aproximadamente. Essa fragmentação possibilitou que os integrantes se sentissem mais a vontade e permitiu que todos os participantes acompanhassem as conversas.

No entanto, a partir da experiência parcialmente negativa, foram analisados alguns fatores recorrentes, que dificultavam o bom andamento dos trabalhos:

- Excessivo número de mensagens

- Mensagens fora do contexto do grupo

- Mensagens, áudios e vídeos encaminhados

- Mensagens e Imagens de saudação (Bom Dia, Boa Tarde e similares) 
V Congresso Brasileiro de Informática na Educação (CBIE 2016)

Anais do XXVII Simpósio Brasileiro de Informática na Educação (SBIE 2016)

A partir das reflexões sobre os obstáculos encontrados, foram estabelecidas algumas estratégias para a otimização dos grupos.

\section{Estratégias para a otimização de grupos colaborativos}

Após o refinamento de experiências anteriores, as seguintes práticas foram identificadas como produtivas para a construção de grupos colaborativos mais eficazes:

- Uso de imagens com código QR, fornecendo informações que se deseja compartilhar:

É mais fácil encaminhar uma imagem do que fragmentos textuais ao grupo. Imagens bem organizadas e padronizadas contribuem para propagar as informações. Para facilitar o entendimento dos participantes, os textos foram padronizados como "não-oficial" e "oficial". Os textos finais, já aprovados em todas as esferas, foram disponibilizados em uma formatação mais elaborada.

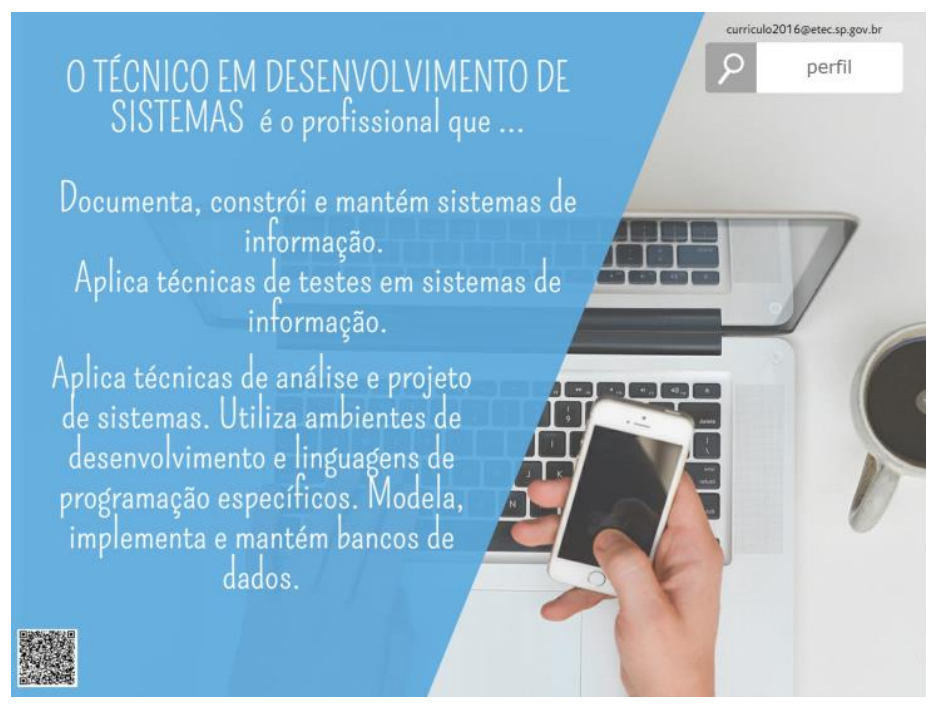

Figura 1. Modelo de Imagem de Divulgação. Fonte: o autor, 2016.

-Definição de regras claras, evocadas nas primeiras semanas dos cursos, até que o comportamento seja firmado;

-Correção de comportamentos indesejados, gentilmente, na mesma hora em que ocorrem;

-Respostas à mensagens de forma rápida;

•Utilização do status (“disponível” significa que você pode dar atenção);

-Delimitação de conteúdo e horário;

-Realização de pesquisas curtas;

-Uso da plataforma web do WhatsApp, para maximizar o trabalho;

-Abertura para que os participantes se expressem mesmo quando não concorde com eles.

O principal objetivo da criação de grupos colaborativos é a captação de sugestões e propagação de informações entre os coordenadores de curso e a equipe de elaboração 
V Congresso Brasileiro de Informática na Educação (CBIE 2016)

Anais do XXVII Simpósio Brasileiro de Informática na Educação (SBIE 2016)

curricular. Tais grupos permitem que os saberes sejam compartilhados e multiplicados, mas isso geralmente surgem em meio a relatos não relevantes ao currículo, o que exige sensibilidade para não ferir ou desestimular as contribuições, respeitando as normas estabelecidas.

\section{Considerações finais}

Como resultado parcial, observou-se que cerca de $80 \%$ dos Coordenadores do Curso de Informática (modalidade modular) no estado de São Paulo, estão participando desse trabalho colaborativo. Após a segunda semana da criação dos grupos regionais, não houve incidentes relativos ao mau uso da ferramenta. Algumas sugestões apresentadas nos grupos foram adicionadas ao currículo até junho de 2016. Considerando que o processo ainda está em desenvolvimento, espera-se que esse número aumente a partir da divulgação da matriz curricular. As equipes de elaboração podem consultar os grupos e tirar dúvidas antes de inserir novas tecnologias ao currículo. Esses grupos também estão possibilitando o mapeamento de parceiros regionais e a construção do perfil regional de empregabilidade nos cursos do eixo de Informação e Comunicação do Centro Paula Souza.

Tendo como base os resultados obtidos, a utilização de ferramentas como o WhatsApp para a criação de grupos colaborativos mostra-se benéfica e pode corroborar a construção de currículos democráticos.

\section{Referencias}

PERRENOUD, Philippe. Desenvolver Competências ou Ensina Saberes? A escola que prepara para a vida. Editora Penso,2013.

DEMAI, Fernanda. Mello. O trabalho do Laboratório de Currículo do Centro Paula Souza: histórico e organização.. In: CARVALHO, M. L. M.. (Org.). Patrimônio, currículos e processos formativos... São Paulo: Centro Paula Souza, 2013, v. 1, p. 357-376.

DAMIANI, M. F. Entendendo o trabalho colaborativo em educação e revelando seus benefícios. Revista Educar, Curitiba, n. 31, p. 213-230, 2008. Editora UFPR.

NETO, Alício Rodrigues da Silva. Currículo e Comunidades de Aprendizagem - Uma abordagem contemporânea. Anais do SBIE 2010.

RAMOS, Marise N. Concepção do ensino médio integrado. Texto apresentado em seminário promovido pela Secretaria de Educação do Estado do Pará nos dias 8 e 9 de maio de 2008. 